\title{
Media Environment in Dynamical Reproduction and Strengthening of Ideological Routine
}

\author{
Yury Grigorievich Volkov ${ }^{1}$, Maria Anatolyevna Dakoro ${ }^{1}$, Svetlana Igorevna Imgrunt ${ }^{1} \&$ Eugenia Sergeevna \\ Sagalaeva $^{2}$ \\ ${ }^{1}$ Institute of Sociology and Regional Studies, Southern Federal University \\ ${ }^{2}$ Institute of Law, North-Caucasus Federal University \\ Correspondence: Yury Grigorievich Volkov, Pushkinskaya street, 160, Rostov-on-Don, 344005, Russian \\ Federation. Tel: 78-6-3264-1755. E-mail: infoippk@sfedu.ru
}

Received: March 30, 2015 Accepted: April 20, 2015 Online Published: May 14, 2015

doi:10.5539/res.v7n7p216 URL: http://dx.doi.org/10.5539/res.v7n7p216

\begin{abstract}
The article covers the research of media environment factors in dynamical reproduction and strengthening of ideological routine that allows to connect media environment and media culture with dominating routine conceptions in dialectical shift from past to present. The authors emphasized that conceptual and philosophical interpretation and articulation of everyday routine in the context of historical path of routine problems formation in humanities knowledge, allows to reconstruct and interpret the bygone reality "from within", i.e., through understanding a pattern of thoughts and conduct of individuals, as social actors. The article shows that media environment in dynamical reproduction and strengthening of ideological routine correlates with reconstruction of dominating routine perceptions in dialectical shift from past to present. Since ideological dimension of everyday routine means that everyday practices obtain certain value and meaning, in this regard, reproduction and strengthening of ideological routine occurs, first of all, through development of elementary ideological concepts and ideas by professional ideologists, aimed at the primitive level of comprehension; secondly, through independent elaboration of ideological views and opinions by individuals in their daily life based on common sense.
\end{abstract}

Keywords: ideology, everyday routine, ideological routine, routine reproduction, reproduction of ideology, media environment

\section{Introduction}

In the context of vital rhythm acceleration, modern life inevitably actualizes various forms of routine existence, creating a kind of "ideological montage". Ideology artefacts gradually assimilate a variety of symbolic means that help people to find their place in social reality. That said media environment gains a significant role in modern conditions.

Media environment is a set of conditions, in the context of which media culture operates, i.e., this is a sphere that connects people with everyday routine, informs, entertains and promotes certain moral and aesthetic values, exerts ideological or any other effects on estimates, opinions, and behavioral orientation of people through mediation of mass media.

According to N. B. Kirillova, the information age, in the first instance, is associated with the global media environment, creation of a unified global information space. In fact, it is a new information civilization, associated with an enormous and unprecedented influence of modern "information industry" on almost all aspects of public life. It is about human development towards a new way of thinking with information awareness as a basis and intelligence as a password (Kirillova, 2005).

Media environment in dynamical reproduction and strengthening of ideological routine manifests itself in everyday media culture - a set of information and communication means, elaborated by humankind in the process of historical development.

Media culture is also a semiotic system with its own "language" and "codes" for transmission of realias, performing multifunctional role in representation process. Media culture includes a culture of information transmission and its perception; it serves both as an indication of development level of a personality that is able 
to read, analyze, evaluate media texts, create media art, etc.

Routine media culture, in its turn, relates to the values, norms, meanings, and patterns, regulating the use of mass-communication tools located in the home environment.

In the semantic space of the theory of practice, media culture is permanently reproduced and transformed due to the behavior of people (actors) who make their practical choice. Routine media culture varies in parameters and characteristics of daily activities. This includes practices related to obtaining news, transfer of experience and knowledge through mass media, recreation, entertainment, creativity, and, finally, to the means of communication, mediated by mass media (Sergeeva, 2011).

The phenomenon of everyday routine is a difficult and complex issue considered by social philosophers for a long time. E. Husserl was among the first who turned attention to the problems of everyday routine (Husserl, 1913). His approach to the study of this phenomenon can be characterized as a phenomenological and hermeneutical. Routine is a basis of social being and common sense in the social phenomenology.

Everyday routine was on the radar of scientific and theoretical self-consciousness of such researchers as M. Weber (Weber, 1999), H.-G. Gadamer (Gadamer, 2004), A. Schutz, and M. Heidegger (Heidegger, 2010).

E. Husserl and A. Schutz introduced the concept of "lifeworld" into the language of science, which became one of the first constructs describing the everyday routine environment (Ruggerone, 2012).

Over the last decades of the twentieth century, everyday routine serves as a specific subject of social and humanitarian disciplines, facilitating formation of various schools, studying this phenomenon. The following schools are worth noticing as well: the German school of "History of everyday routine" (founders: H. Medick \& A. Ludtke), the school of "microhistory" in Italy (founders: C. Ginzburg, J. Levi, \& E. Grendi) (Smirnov, 2013).

As to the relationship of everyday routine and ideology, the basic concepts of E. Durkheim and K. Mannheim certainly should be noted. These concepts consider the phenomenon of ideology resulting from people living together, from their natural and socio-historical circumstances. E. Durkheim interpreted the ideological forms as the main factor consolidating social system (Durkheim, 1982).

Methodological issues of correlation and interrelation of ideology and science, ideology and truth are considered in the works of M. Weber., K. Mannheim (Mannheim, 1950), R. Merton, J. S. Mill and Pareto (Pareto, 1966).

Conceptual and philosophical interpretation and articulation of everyday routine in the context of historical path of routine issues formation in humanities knowledge allows to reconstruct and interpret the bygone reality "from within", i.e. through understanding a pattern of thoughts and conduct of individuals, as social actors.

\section{Research Methodology}

Provisions and conclusions of R. Bourdieu (Bourdieu, 1992) and J. Habermas serves as the basis of theoretical and methodological construct, which represent the fundamental provisions of the life-world individualization as an everyday routine. The following theories also played an important role: the phenomenological theory of the lifeworld by E. Husserl; the procedural theory of everyday routine by H.-G. Gadamer; the systematic theory of things by Baudrillard (Kellner, 1994).

The following theoretical approaches serve as a basis for the author's theoretical and research construct, allowing ideological interpretation of everyday routine: a) the process approach; b) the ideology and value structure of everyday consciousness; c) paradigm of symbolic politics and symbolic exchange; d) phenomenological anthropology and phenomenological psychology. This integrated approach helps to outline semantic contours of the research field problems and develop the concept of ideological everyday routine, as well as to identify and analyze the processes of reproduction of the ideological everyday routine in the media environment.

The French philosopher M. Foucault named the research method for discursive practices, as well as their relationship with socio-cultural circumstances, the "Archaeology of knowledge", focusing on the concept of "power-knowledge" (Foucault, 1996). Today the power of information and media become evident both around the world and in Russia. Hence, the specific function of media culture is to serve for integration of Russian modernization at the turn of the 20th and the 21 st century.

Researchers more frequently pay attention to the fact that the increasing dependence of everyday human activities on technical and technological means of information and communication is in the list of socially significant problems that have noticeable influence on life of both individuals and the entire society. Person of modern society develops, socializes, and acts in mega informational space created by the mass media.

However, one of the most topical scientific issues reside in the fact that consequences of newly appearing means 
of communication and information are subject to analysis mainly in the broader context of social, political, and economic facts. At the same time, the subject of down-home routine that over the last century has integrated communication technologies and devices profoundly changing the socio-cultural environment of the human habitat remains poorly developed.

Each new variety of mass media, penetrating into everyday routine, initiates a new experience of social information processing. However, the information revolutions do not represent a straightforward process, where new types of media just come into use and take their place in down-home routine of the human individual. It would it be more accurate to speak of the diverse processes of media acculturation or, if to consider the domestic sphere of human life, about the processes of domestication of media technologies (Sergeeva, 2011).

Media environment in dynamical reproduction and strengthening of ideological routine correlates with reconstruction of dominating routine perceptions in dialectical shift from past to present.

The methodology of routine sociology and methods of qualitative approach allows developing a sociological interpretation of media culture.

The principles of studying everyday routine involve "comprehensible" review and detailed description of diversity of cultural standards and skills manifesting themselves in everyday use of communication tools.

In this regard, O. V. Sergeeva understands the routine media culture as a set of values, norms, patterns, practices, and processes, governing the practices and processes of using mass media, localized in the down-home private environment: the practices of receiving news; the practices of sharing experience and knowledge through media; the practices of relaxation, entertainment, creativity possible due to mass media; and the communication practices. Media culture, according O. V. Sergeeva, is a kind of culture, similar to political, economic or legal culture, and it plays the role of social processes regulator in creation, transmission and storage of socially significant information (Sergeeva, 2011).

We have already drawn attention to the fact that ideological dimension of everyday routine means that everyday practices obtain certain value and meaning. Ideology permeates throughout mundanity, reflecting in hopes and expectations of ordinary people. In this regard, reproduction and strengthening of ideological routine occurs in two ways: a) professional ideologists develop simple, fundamental ideological concepts and ideas aimed at a primitive level of comprehension; b) ideological views and ideas are elaborated independently by individuals in their daily life (Volkov \& Malitski, 2004).

Accordingly, the ideological routine as a functional area of social life is reflected in the values of everyday routine, in a complex of ideas and images, used by people to perceive, experience, and evaluate actual conditions of their existence.

According to O. V. Sergeeva, this view of culture, developed by the theory of practices, distracts sociological attention from the perceived ideas and values to the automatic behavior and inertness of habitual things. Based on the phenomenological provisions of sociology of knowledge, the tradition of studying practices recognizes mundane competence of an individual as a significant explanatory scheme.

Therefore, the category of "social practice" means regularly reproducible actions based on the person's knowledge of situation and his/her ability to cope with the conditions of such situation physically, mentally, and verbally. Following the principles of this theory makes it possible to study not only the conventional methods of using symbolic determinations, including language and etiquette, but also a variety of artefacts. The theory of practices allows tracking a new domain perspectives and viewpoints, focusing on subjective methods of information handling.

Significant role of media environment in dynamical reproduction and strengthening of ideological routine is associated with development of media worldview at the level of mundane consciousness.

I. V. Rogozina proceeds from the premise that mass media are a specific social tool for reality perception, required for stabilization and self-organization of society and its evolution. Each media-communicative channel has its own cognitive style, expressed in actualization of the results of reality media-cognition by means of a specific "toolkit" of dominating integrative structures. Media-communicative activity is a hierarchical cognitive process that presupposes perception of reality fragment by media text producer. Based on the mental-cognitive mechanisms, producer verbalizes a relevant part of the psychic reality, transforming it into a message or symbolic reality (Rogozina, 2009).

In the course of media worldview formation, taken in conjunction with dynamical reproduction and strengthening of ideological routine, media environment becomes a space for implementation of various 
manipulative strategies.

I. V. Annenkova proceeds from the premise that the interpretative activity of domestic mass media today takes place in line with four main strategies that have previously been formed in the West. These are: 1) the manipulation strategy; 2) the hedonistic strategy; 3) secularization strategy; and 4) the culture shock strategy. The manipulation strategy is the primary one in relation to the other three strategies and is constant regardless of the ideological field of various mass media and mass-communication tools. Its specific feature resides in the fact that it seems like being dissolved in all other strategies or, more specifically, serves as a kind of a transparent dome over them.

This strategy has overshadowed such strategies as propaganda and agitation that, largely, involves open impact on the object. Today, mass media creating own worldview and offering such view as the only possible destination for mass addressee use a factor of confidence and try to form an opinion about such worldview as an objective one. Therefore, open propaganda shifts to the periphery of discursive activity of mass media (Annenkova, 2012).

Characterizing the dynamical reproduction and strengthening of ideological routine, the social and philosophical approach presumes that ideology is a system of live knowledge of ideas and is implemented in form of experience and practice. Ideological knowledge and values fulfil important public functions, organizing and controlling joint activities of people in various spheres of public life. In turn, ideological relations are relations between people in the process of both creation and dissemination of ideas and images in the society.

Images, formed in collective conscious, have active impact on both individuals and social processes. Specific feature of such images reside in the fact that they have little in common with the actual everyday routine, experiencing the impact of "the trivial round", as well as intentions coming "from above".

Hence, hypocrisy comes "from above" in a form of ideology and self-deception comes "from below" as a component of the ideological everyday routine. Therefore, social philosopher T. A. Shalyugina is right in many respects, describing a large-scale process observed in the Russian society as creation of self-sufficient simulative mental images.

According to Shalyugina, the leading characteristics of social consciousness include the following: ability to consolidate masses based on emotional bond to the common faith and common purpose; joint perception, understanding and recognition of information perceived by masses; active influence of mass opinion on the social process; possibility to misinform the masses in the absence of personal choice; manipulating mass consciousness by means of mass media and mass culture (Shalyugina, 2011).

These simulative images are reproduced in the society, where escape from reality to illusory fantasies and self-deception is highly pervasive. Simulative images of mass consciousness are superimposed on despiritualization of the society. Formation of simulation images in mass consciousness is also facilitated by the fact that "human-mass" behavior is governed not by abstract values, but by "instincts"- basic needs related to the necessity of physiological human survival and gaining access to a set of social benefits, such as but not limited to money, power, and social status with a variety of privileges.

The variety of contradictions emerging in the society is preconditioned by such factors as inequality of social status of different social strata and perspectives of social mobility, the nature of the interaction with social and political institutions as the main source of social uncertainty; the general controversial progress of social and cultural changes in the environment of the "modern time challenge".

Media environment in dynamical reproduction and strengthening of ideological routine manifests itself as ideology refracted through day-to-day existence of a person, being a part of public relations, as well as ideologically saturated everyday routine.

Media environment appears in a society, where political and social subjectivity is largely lost, i.e. individuals are not able to set socially sufficient goals and achieve them, while the social reality is becoming "fuzzier" and more uncertain. The social reality is in the process of continuous creation and is dependent on public consciousness, perceptions, and interpretations.

According to A. V. Kachalkina, "the social reality is predetermined by methods applied by a person for its development and transformation" (Kachalkina, 1999).

Domestic researcher V. V. Tsygankov draws attention to the same circumstances. According to him, when applied to social semiotic reality, the problematic topic of social reality semiotics causes an ontological contradiction 
between the existing singular social reality and a variety of models of its interpretation and creation, presented in a symbolic form (Tsygankov, 2009).

According A. Schutz, all our knowledge about the world contains constructs, i.e. a set of abstractions, generalizations, formalization, and idealizations that meet a certain level of thinking (Schutz, 2004). Phenomenological sociology distinguishes between mental objects, formed in the routine consciousness of individuals, and second-order constructs prevailing in social studies and humanities. In this regard, media environment in dynamical reproduction and strengthening of ideological routine correlates with comprehension of functional significance of symbols in the process of ideological routine formation and representation.

A modern day person lives not only in the real world, but also in the world of symbols.

Social philosopher M. A. Shtanko presumes that symbol is a cultural phenomenon and includes socially predefined structures of meanings, within which human individuals are engaged in social action. Symbol is a "bridge" that allows "to restore order to mind". Thus, the process of accumulation of meanings (symbolic experience) allows a person to "fit" into the surrounding world (Shtanko, 2004). Therefore, in the modern society such semantic and meaning formation phenomena as characters receive special importance and significance.

Processes unwrapping within the environment of symbolic construction of social reality in routine existence can be implemented in several specific ways, which can not only reveal the features of joining the social world, but also trace the degree of involvement of the main social space components into these processes.

Bourdieu had the following opinion in this regard: To change the world, you need to change the way it is forming, i.e. outlook and practical operations that serve for formation and reproduction of groups (Bourdieu, 1994).

In turn, domestic sociologist and philosopher B. V. Dubin believes that in the actual everyday routine, whether it is the present day reality or history, it makes sense to distinguish between different spatial characteristics of symbols and symbolic structures (sets, "chains"). Symbols divide, represent, organize actions in horizontal plane, for instance, separating "us", "our" from "them", "alien", and in vertical plane-pointing out the actions of lower or higher classes, origin or, in the most general terms, the local, "terrestrial" world and the world beyond, the "heavenly" world.

However, the symbols may relate to different periods, layers of events and actions, referring to the past, present or future, the beginning or end, change and recovery, thus characterizing certain events in terms of creation or destruction, chaos or order.

According to philosopher Y. B. Kondratyeva, the provision stipulating that the world has symbolic nature is quite common in modern social sciences and humanities. Symbol acts as a basic and universal structure-forming element of the process of cognition and "creation" of world. Everyday life and the entire existing socio-cultural environment is impregnated with symbols.

The entire world and social reality become symbolic. Understanding of the world as a symbolic reality, revealing the specifics of symbolic activity in various spheres of public life, the role of symbolization as not only a separate phenomenon, but also a phenomenon of mass consciousness, call for an urgent in-depth analysis of the symbol's place and role in cognition and activities.

\section{Conclusions}

Herewith, in the context of vital rhythm acceleration, modern life inevitably actualizes various forms of routine existence, creating a kind of "ideological montage". Ideological artefacts start to include not only theoretical doctrines, but also a variety of symbolic means - ordinary perceptions, attitudes, images, and texts used by an individual to interpret his/her place within the social reality and to acquire a sense of identity and motivation for social activity.

Herewith, in current conditions, media environment plays significant role, i.e. this is a sphere that connects people with private world, informs, entertains and promotes certain moral and aesthetic values, exerts ideological or any other effects on estimates, opinions, and behavioral orientation of people through mediation of mass media.

Media environment in dynamical reproduction and strengthening of ideological routine manifests itself in media culture - a set of information and communication means elaborated by humankind in the process of historical development. Media culture is also a semiotic system with its own "language" and "codes" for transmission of realias, performing multifunctional role in representation process. In turn, the routine media culture is understood 
as a set of values, norms, patterns, practices and processes, governing the use of mass media, localized in the down-home environment:

Media environment in dynamical reproduction and strengthening of ideological routine correlates with reconstruction of dominating routine perceptions in dialectical shift from past to present. Given that the ideological dimension of everyday routine means that everyday practices obtain certain value and meaning, reproduction and strengthening of ideological routine occur in two ways: a) professional ideologists develop simple, fundamental ideological concepts and ideas aimed at a primitive level of comprehension; b) ideological views and ideas are elaborated independently by individuals in their daily life. Accordingly, the ideological routine as a functional area of social life is reflected in the values of everyday routine, in a system of ideas and images used by people to perceive, experience, and evaluate actual conditions of their existence.

Characterizing dynamical reproduction and strengthening of ideological routine, the social and philosophical approach presumes that ideology is a system of live knowledge of ideas and is implemented in the form of experience and practice. Ideological knowledge and values fulfill important public functions, organizing and controlling joint activities of people in various spheres of public life.

In turn, ideological relations are relations between people in the process of both creation and dissemination of ideas and images in society. Symbolic images, formed in collective conscious, are capable of exerting active influence on both individuals and current social process. Specific feature of such images reside in the fact that they have little in common with current reality, experiencing the impact of "the trivial round".

Media environment in dynamical reproduction and strengthening of ideological routine manifests itself as ideology refracted through day-to-day existence of a person being a part of public relations, as well as ideologically saturated everyday routine.

\section{References}

Annenkova, I. V. (2012). Modern media view of the world: Neo-rhetorical model (linguo-philosophical aspect). Moscow: Moscow State University.

Bogolyubova, S. N. (2011). Everyday Routine: Space of Social Identity. Moscow: Social and humanitarian knowledge.

Bourdieu, P., \& Wacquant, L. J. D. (1992). An Invitation to Reflexive Sociology (p. 97). Chicago and London: Univ. of Chicago Press.

Bourdieu, P. (1994). Origins. In the Social space and symbolic power. Moscow: Socio-Logos.

Durkheim, É. (1982). The Rules of Sociological Method. New York, London, Toronto, Sydney: The Free Press. Retrieved from http://comparsociology.com/wp-content/uploads/2013/02 /Emile-Durkheim-Rules-of-Sociological-Method-1982.pdf

Foucault, M. (1996). Archaeology of knowledge. Kiev: NICA CENTER.

Gadamer, H.-G. (2004). Truth and method. (2nd ed., p. 601, p. 273). Chicago: Continuum.

Heidegger, M. (2010). Being and Time. Albaniae: State University of New York Press.

Husserl, E. (1913). Ideen zu einer reinen Phänomenologie und phänomenologischen Philosophie: Buch 1. In Allgemeine Einführung in die reine Phänomenologie. Retrieved from http://www.freidok.uni-freiburg.de/volltexte/5973/

Kachalkina, A. V. (1999). Social reality as the object of philosophic analysis: Probabilistic aspect. (Synopsis of a thesis of Doctor of Philosophy). Volgograd: Volgograd State Technical University.

Baudrillard, J. (1994). A Critical Reader. Oxford: Basil Blackwell.

Kirillova, N. B. (2005). Media environment of Russian modernization. Moscow: Academic project. Retrieved from http://edu.of.ru/attach/17/

Mannhaeim, K. (1950). Freedom, power and democratic planning. L.: Oxford University Press.

Pareto, V. (1966). Sociological Writings. N.Y.: Praeger.

Rogozina, I. V. (2009). Media view of the world: Cognitive semeiotic aspect. (Synopsis of a thesis of Doctor of Philology). Barnaul: Altai State University.

Ruggerone, L. (2013). Science and Life-World: Husserl, Schutz, Garfinkel. Human Studies, 36(2). http://dx.doi.org/10.1007/s10746-012-9249-6 
Schutz, A. (2004). Selectas: Glowing sense of world. Moscow: Russian Political Encyclopedia.

Sergeeva, O. V. (2011). Mediaculture in routine practices. (Synopsis of a thesis of Doctor of Social Science). Saint Petersburg: Saint Petersburg State University.

Shalyugina, T. A. (2011). Imitation in modern Russian society: Essence, subjects of the impact, social environment of occurrence. Rostov-on-Don: North Caucasus Scientific Centre of the Higher School, Southern Federal University.

Shtanko, M. A. (2004) Philosophical issues of political reality formation: Symbolic aspect. (Synopsis of a thesis of Candidate of Philosophical Sciences). Tomsk: Tomsk State University.

Smirnov, A. V. (2013). Conceptualisation of everyday routine: Historical and methodological aspects. (Synopsis of a thesis of Doctor of Philosophy). Saint Petersburg: Saint Petersburg State University.

Thurman, R. A. F. (1980). Philosophical Nonegocentrism in Wittgenstein and Candrakirti in Their Treatment of the Private Language Problem. Philosophy East and West, 30(3). http://dx.doi.org/10.2307/1399191

Tsygankov, V. V. (2009). Theoretical and methodological foundations of the study of social reality significance. In Izvestya, Herzen State Pedagogical University of Russia (p. 96). Saint Petersburg.

Volkova, Y. G., \& Malitsky V. S. (2004). Ideology and humanism. Moscow: Socio-Humanitarian Knowledge.

Weber, M. (1999). Sociological writings. Retrieved from https:/www.marxists.org/reference/subject/philosophy/ works/ge/weber.html

\section{Copyrights}

Copyright for this article is retained by the author(s), with first publication rights granted to the journal.

This is an open-access article distributed under the terms and conditions of the Creative Commons Attribution license (http://creativecommons.org/licenses/by/3.0/). 